\title{
Una ensoñación reactiva al poder: la crisis de la Logia Virtud en el marco de un conflicto simbólico (1911-1921)
}

\author{
MARTíN MUÑOZ ZAFRA \\ CEHME
}

\begin{abstract}
A Reactive Dream to Power: the crisis of the «Virtud» within framework of a symbolic conflict (1911-1921)
\end{abstract}

\begin{abstract}
RESUMEN
ABSTRACT

Se sostiene en este artículo cómo en un

This article argues how the break of lodge contexto de enfrentamiento clericalVirtud is not only caused by the clericalanticlerical la quiebra de la logia Virtud se ve asimismo afectada por la disidencia interna. A principios del siglo xx los partidos republicanos locales adquieren relevancia sólo en cuanto se incorporan a una lucha simbólica en búsqueda del progreso y la moralidad.

PALABRAS CLAVE: anticlericalismo, masonería, republicanismo, laicidad, poder simbólico, anticlerical confrontation but by inner dissenters too. In the early 20th century the local republicans parties acquire meaning only insofar as they can be subsumed in a symbolic fight in search of progress and morality.

KEYWORDS:

anticlericalism, masonry, republicanism, laicism, symbolic power, myths, conflict.

mitos, conflicto.

«Eso. Eso, es lo terrible: la gente saludable, la gente inteligente, que está marcando el paso. Porque ésos no van engañados. No» ${ }^{1}$.
\end{abstract}

\footnotetext{
${ }^{1}$ Carpentier, A. 2004: La consagración de la primavera. Madrid, Alianza Editorial, pág. 124.
} 


\section{INTRODUCCIÓN}

Nos dicen los antropólogos que la cultura es una descripción aportada por el investigador sobre el comportamiento y la comprensión sociales de los grupos humanos, y que esta descripción, cuyo medio específico es el aprendizaje social, se despliega, se desarrolla, en procesos de significación ${ }^{2}$. Igualmente se nos recuerda que el ser humano es un productor de códigos, y un código es una fórmula convencional que ordena la interacción de los individuos, reglas, en fin, socioculturales ${ }^{3}$. Este ordenamiento de las conductas y de los comportamientos, además, no es simple retórica, sino que construye la realidad. Es en este plano donde los símbolos se revelan como formidables herramientas para obtener, y apuntalar estructuras de poder, para consolidar concepciones del mundo. En este artículo mostramos cómo el compromiso secularizador de la masonería, en este caso de la masonería local malagueña en un momento muy concreto de su historia, se ve constreñido por un proceso de lucha por el poder, en concreto por el poder simbólico. Esta rivalidad se evidencia, en este caso particular y con la raigambre adquirida en décadas anteriores, en un oscuro enfrentamiento entre jesuitismo y masonería.

No querríamos recurrir al expediente de comprender en su conjunto el anticlericalismo como respuesta o en función de la acción clerical, pero otorgar o conceder alguna autonomía al fenómeno anticlerical, como pura búsqueda laicista y racional ajena al conflicto simbólico, la tarea de sustraerlo a esa polaridad sería, ciertamente enrevesada.

Éste, por otra parte, no pretende ser un estudio sobre el antimasonismo ni persigue enfatizar la negligencia clerical, cometido que, desde luego, es factible y aceptable, y es que nos encontramos en el contexto de la lucha por la afirmación simbólica como espacio de poder, «el espacio organizativo como frente asociativo liberal y republicano ${ }^{4}$, en el que convergen sociedades progresivas, masones, librepensadores, socialistas y, desde luego, republicanos.

Julio de la Cueva nos define el anticlericalismo, en un sentido amplio, como «resistencia al poder del clero, a su intrusión en la vida pública», más concretamente «como la oposición al intento de clérigos y laicos católicos de controlar ideológicamente la sociedad desde una posición de privilegio» 5 .

El republicanismo como heredero de un pensamiento ilustrado radicalizado, concibe una forma de religión que se aproximaría a la expuesta perspicuamente

2 Díaz de RAdA, Á. 2006: Etnografía y Técnicas de Investigación Antropológica. Madrid, UNED, pág. 97.

3 Ibíd., págs. 67-68.

${ }^{4}$ BASTIAN, J. P. 2001: Masonería y Protestantismo en España: un balance historiográfico, en FERRER BeNIMELLI, J. A. (coord.) La masonería española en el 2000. Una revisión histórica. Zaragoza, CEHMEGobierno de Aragón, págs. 87-94.

${ }^{5}$ De la Cueva Merino, J. 2001: Balance y tareas en el estudio del anticlericalismo español: una perspectiva desde la historia de la masonería, en FERRER BenimelLI, J. A. (coord.) La masonería española en el 2000. Un revisión histórica. Zaragoza, CEHME-Gobierno de Aragón, pág. 26. 
por Rousseau en Del Contrato social, esto es, una religión civil estabilizadora de la república. Una especie de religiosidad mínima postulada por el Estado, no excluyente y tolerante:

«Los dogmas de la religión civil deben ser simples, pocos, enunciados con precisión, sin explicaciones ni comentarios. La existencia de la divinidad poderosa, inteligente, bienhechora, previsora y providente, la vida por venir, la felicidad de los justos, el castigo de los malvados, la santidad del contrato social y de las leyes: he ahí los dogmas positivos. En cuanto a los dogmas negativos, los limito a uno solo: es la intolerancia; entra en los cultos que hemos excluido» 6 .

Es por tanto una suerte de deísmo, la religión civil del Estado... Pero «una sociedad de ciudadanos plenamente virtuosos no sólo sería farisaica y ultrapuritana, sino que conduciría a la postre a la imposición violenta de la virtud»?

Evidentemente la cultura republicana era refractaria a una Iglesia católica que aportaba su propia ética cristiana o que, por ejemplo, acaparaba gran parte de la educación escolar, es decir, confesional. De la Cueva Merino subrayó algunos matices de esta actuación:

«La movilización anticlerical fue en gran medida criatura de la actuación interesada de los grupos republicanos. Por un lado, el anticlericalismo y la secularización del Estado y - según qué casos- de la sociedad formaban parte tradicional del programa republicano; por otro, el anticlericalismo se integraría eficazmente en la demagogia populista a la que buena parte del republicanismo español se entregó, con cierta fortuna, en esta primera década del siglo XX»»8.

Señala Luis P. Martín que, como los ataques desde la Iglesia se hacían debido a la libertad de conciencia que se ejercía y propalaba desde las logias, "el anticlerismo masónico surge a causa del antimasonismo clerical, y no al revés "», y su ataque se aplica especialmente en lo institucional, y no tanto en lo rigurosamente religioso. Sin embargo sí se dio un anticlericalismo popular, antropológico, tradicional o, si se quiere, ancestral, más propenso a la denuncia y al conflicto, que la exposición positiva y argumentada de la laicidad, en definitiva un clericalismo como «cultura», como mito movilizador:

${ }^{6}$ Rousseau, J. J. Del Contrato social, IV, 8.

7 GineR, S. 1998: Las razones del republicanismo, en Claves de Razón Práctica, núm. 81, pág. 7.

8 De La Cueva Merino, J. 1997: Movilización política e identidad anticlerical, 1898-1910, en Ayer, núm. 27, pág. 108. Sagrario Torres propone una definición de populismo: «movimiento político (o la fase de un movimiento más amplio) que se basa, para su eficacia, en amplias movilizaciones de masas a partir de una retórica de contenido fundamentalmente emocional y autoafirmativo, centrada en torno a la idea de «pueblo" como depositario de las virtudes sociales de justicia y moralidad, y vinculada a un líder, habitualmente carismático, cuya honestidad y fuerza de voluntad garantiza el cumplimiento de los deseos populares». Véase Torres Ballesteros, S. 1997: Los populismos, en RoIz ParRa, F. J., et alii Fundamentos de Ciencia Política. Madrid, UNED, pág. 465.

9 Martín Martínez, L. P. 2004: El anticlericalismo en la masonería española (1900-1931), en Ferrer BenIMELLI, J. A. (coord.) La Masonería en Madrid y en España del siglo XVIII al XXI. Zaragoza, CEHME-Gobierno de Aragón, págs. 384-385. 
«El anticlericalismo no consistió sólo, pues, en ideología y retórica, sino que también implicó movilización antieclesiástica y sacrofóbica, más o menos cargada de simbología y ritualismo, más o menos teñida de confrontación y violencia» ${ }^{10}$.

Javier Otaola distingue entre un anticlericalismo político, ligado a las luchas democráticas contra el sistema del Antiguo Régimen, y un radicalismo radical ontológico, «que tiene su expresión paradigmática en el anticlericalismo sustantivo y ateo de Nietzsche, una ateísmo como necesidad moral»11.

El discurso movilizador republicano, la mítica republicana, persigue así la secularización del pensamiento, el racionalismo ilustrado, y no está tan caracterizada su acción en la lucha de clases como en el anticlericalismo. El potencial movilizador de esta red de organizaciones que constituye el espacio de sociabilidad republicano es reflejo y motor de una voluntad anticlerical que se desarrolla en otros foros $^{12}$, es decir, el asociacionismo político republicano, como espacio de acción, traduce la urgencia secularizadora de los promotores de una religión cívica. Por otra parte recordemos que el republicanismo español, como otros radicalismos populares del momento, emerge de la contestación a los procesos de exclusión política y moral que se suceden en el régimen restauracionista. Declaraba Juan Sol y Ortega que «sin sacrificio no hay redención; supuesto que aspiramos al noble papel de redentores, seámoslo de verdad y no de opereta» ${ }^{13}$, pero la redención era malograda de forma original por los elementos más beligerantes de la dualidad trono-altar con el fin de «librar sin tregua ni descanso batalla a la Masonería, a la Ciencia y al Progreso». El procurador Ponce de León y Correa, Simb. Jesús, se dirige a la Gran Asamblea del GOE que él mismo preside en 1917, y allí define la labor de los jesuitas con estas palabras:

«A la sombra de una religiosidad y del amor a la monarquía, que nunca han sentido, pretenden los sectarios de tan funesta institución apoderarse por completo de lo que queda de nuestra desgraciada España, para gobernarla a su antojo, acaparando para ello, no sólo las riquezas para gustar con mayor comodidad de los beneficios terrenales, sino lo que es más triste y doloroso, acaparando la enseñanza de la juventud, con lo que conseguirán, si no nos oponemos, hacer el día de mañana un pueblo de eunucos, ignorantes y envilecidos ${ }^{14}$.

10 De la Cueva Merino, J. 2001: pág. 28.

11 Otaola, J. 2001: Anticlericalismo y laicidad, en Claves de Razón Práctica, núm. 117, págs. 59-62

12 En 1892 el Gran Oriente de España brindó una encuesta sobre temas considerados relevantes de la sociedad del momento: anticlericalismo, jesuitismo, pacifismo y cuestión social. Véase SANLLORENTE BARRAGÁN, F. 1999: Anticlericalismo, pacifismo y cuestión social en las logias del Gran Oriente de España (1890-1895), en FeRRER BenimeLLI, J. A. (ed.) La masonería española y la crisis colonial del 98. Zaragoza, CEHME-Gobieno de Aragón, págs. 223-236.

13 «Política republicana. Opinión de Sol y Ortega», El Popular, Málaga, 29 de diciembre de 1910, pág. 1.

14 «Programa de trabajos masónicos, presentado por la Log. . Virtud. A la Gran Asamblea del Gran Oriente Español», en Boletín Oficial del Gran Oriente Español, núm. 303. Madrid, 31 de julio de 1917, pág. 114. 


\section{EL CONFLICTO SIMBÓLICO}

La disputa refleja la colisión de dos concepciones del mundo. María José Lacalzada nos decía que «unos tenían construida su antropología en clave etnocéntrica, los otros en clave antropocéntrica» ${ }^{15}$, de ahí el antagonismo:

Libre del poder del Vaticano y emancipada de la influencia clerical, España será lo que debe, lo que quiere ser: un pueblo culto, próspero, europeo. El clericalismo desea tener a España sometida, humillada, fanatizada. Nosotros la queremos emancipada, dignificada, ilustrada, dueña y señora de sí misma y de sus destinos ${ }^{16}$.

La movilización anticlerical brotaba de una raíz ética singularizada por la bondad innata del hombre, la ya mencionada autonomía racional de éste, que surge en el pensamiento renacentista y en los planteamientos contra la conciencia medieval que protagonizara la Reforma. Filosofía y modernidad: en el realismo político de Maquiavelo, en las utopías de Tomás Moro y Campanella, y en el acercamiento a la naturaleza que propugnó Bruno. La persecución de un espacio ético es una empresa en las que los republicanismos y las masonerías van de la mano. La meta, el fin último para el republicanismo, es la consecución de un espacio de participación política en el que prevalezcan los valores morales; los racionalismos se conforman con la implantación de un orden ético en el que el hombre sea el feliz intérprete de un drama fraternal, pero siempre hubo que atraer a los tibios y rescatarlos de una inmoralidad enraizada secularmente. Así, el siguiente comentario fue vertido en el contexto de los trastornos que ocasionó el estreno de una polémica obra de Benito Pérez Galdós en 1901:

«Pueblo meridional el nuestro, lo que la experiencia no enseña y las predicaciones de un Pi y Margall no logran, lo realiza el verbo fogoso de un orador cualquiera y el efecto de las decoraciones teatrales. (...) El futuro drama no será ante las candilejas, sino en la plaza pública, en los clubs y en las conspiraciones revolucionarias $\gg 17$.

En Málaga, en el contexto de las elecciones generales de 1914, y en una velada en la que, al mismo tiempo, se conmemoraba el aniversario de la proclamación de la Primera República, el federal Tomás Alonso, Simb. Pitágoras, Orador de la Gran Logia Simbólica Regional Andaluza en 1912, revela en su discurso:

«que si el hombre es amante de los suyos, será un buen padre o un buen hermano; que si a ese hombre le preocupa lo que le ocurre a su vecino y por las cir-

\footnotetext{
15 Lacalzada de Mateo, M. J. 1999: Un puente entre dos siglos: El «Humanismo liberal» entre masones, presuntos krausistas y heterodoxos varios, en FERRER BENIMELLI, J. A. (ed.) La masonería española y la crisis colonial del 98. Zaragoza, CEHME-Gobierno de Aragón, págs. 415-431, pág. 417.

16 «Al pueblo malagueño», La Unión Mercantil, Málaga, 3 de julio de 1910. También «Mitin anticlerical», El Popular, Málaga, 1 de julio de 1910, y «Contra el clericalismo», en Andalucía Masónica», núm. 27, Málaga, 30 de junio de 1910, págs. 3-4.

17 «Campaña anticlerical», en Boletín Oficial de la Gran Logia Simbólica Catalana-Balear, núm. 13. Barcelona, marzo de 1901, págs. 2-3.
} 
cunstancias por la que atraviese su patria es un gran patriota, y que si el hombre siente los mismos anhelos de libertad, redención y progreso por todos los hombres que pueblan la tierra, es un hombre digno de la admiración universal» ${ }^{18}$.

En 1911 el periodista Fernando Lozano, Simb. Demófilo, director de Las Dominicales del Libre Pensamiento, —recordemos su presencia en el Congreso Universal de Librepensadores de Ginebra en 1902-, se acercó a la logia Virtud para ofrecer una conferencia cuyo título desconocemos. Hubo gran presencia de sociedades: republicanos federales, asociaciones obreras, republicanos del $6 .{ }^{\circ}$ distrito, Juventud Republicana, concejales conjuncionistas... Presiden el procurador José Ponce de León, Simb. Jesús, Ramón Ruiz Mussio, y el diputado a Cortes Pedro Armasa Ochandorena. El incansable propagandista del librepensamiento desarrolló en su discurso las aportaciones de ese ideario en defensa de la Ciencia y del Progreso, y concluyó con estas frases:

«En nombre de la ciencia venimos a proclamar la República Universal. La federación de los pueblos. La demolición de las fronteras. El desarme de los ejércitos. La existencia de una sola Ley. Los derechos del hombre proclamados por nuestros comunes gloriosos padres de la Gran Revolución, y el reconocimiento de un solo poder consagrado a hacerlos cumplir y respetar ${ }^{19}$.

Un año después José Ponce de León y Correa, como Venerable Maestro en propiedad de la Augusta y Respetable Logia Capitular «Virtud», recordó al director de Las Dominicales del Libre Pensamiento en los actos de constitución de la Gran Logia Simbólica Regional Andaluza:

«A propuesta de la Presidencia fue acordado por unanimidad nombrar Gran Maestre Honorario de esta Gran Logia a los llustres y Poderosos Hermanos Don Francisco Álvarez Gran, Maestro actual de la Regional Catalana Balear; al insigne escritor Don Fernando Lozano, simbólico Demófilo y al sabio catedrático Don Odón de Buen»²0.

Pero el conflicto persiste en 1919. El anticlericalismo estaba ya patente en el Reglamento de los federales a principios de siglo. El Centro Republicano Federal, «nueva asociación política y obrera», imprimió su Reglamento, más un Reglamento interior, en agosto de 1907. En el artículo primero se define el objeto de la Asociación: "celebrar actos políticos y de propaganda anticlerical hacia los ideales que persigue y establecer escuelas laicas cuando el estado de fondos lo permita» ${ }^{21}$. El

18 «Velada en la Juventud Republicana», El Popular, Málaga, 17 de febrero de 1914.

19 «En la logia Virtud», El Popular, 16 de enero de 1911, págs. 3-4. Recogidas estas conclusiones de Demófilo en la carta enviada por Ponce de León «A todas las Sociedades progresivas, masones, librepensadores, socialistas y republicanos de esta Ciudad», Málaga, 17 de enero de 1911. Archivo General de la Guerra Civil (AHNS) 764/12.

20 Copia del acta de constitución de la Gran Logia Simbólica Regional Andaluza. Málaga, 22 de mayo de 1912. Archivo de la Subdelegación del Gobierno en Málaga (AGCMa).

21 Reglamento del Centro Republicano Federal de Málaga. Málaga, 1907. Tip. y lit. de Ramón Párraga, 15 págs. 
domingo 29 de junio de 1919 celebran los republicanos locales la fiesta del Programa Federal. Preside José Somodevilla López, Simb. Savonarola 2. ${ }^{\circ}$ y están presentes, entre otros, Tomás Alonso, Simb. Pitágoras, José González Oliveros, Costa 2. ${ }^{\circ}$, Jaime Bosch, Rafael Cobos y Juan del Puerto. Es el programa federal que promulgara Pi y Margall el 22 de junio de 1894. Toma la palabra el Orador Tomás Alonso y apunta:

«la monarquía en España es incompatible con la democracia, y lo que es realizable en naciones con monarquía como Inglaterra y Holanda, en nuestro país es imposible, pues esa larva que se llama jesuitismo lo tiene abarcado todo, desde los centros de enseñanza hasta las más importantes entidades financieras ${ }^{22}$.

En las páginas de Andalucía Masónica, como en la década de los ochenta en Giodarno Bruno, no faltaron sueltos dedicados a reprobar a la Iglesia romana y a su jerarquía. Véase, como muestra, el firmado por Jesús, en el cual Ponce de León acaba con esta reflexión:

"Queda, pues, demostrado, que la Iglesia romana pierde terreno por la guerra que le hacen sus mismos partidarios sin necesidad de que en ello se mezcle la masonería, que tiene además otra misión más alta que cumplir, cual es, la de combatir la tiranía y defender la Libertad y el Progreso, en todas sus manifestaciones» ${ }^{23}$.

El enfrentamiento no fue en estas y en otras circunstancias únicamente verbal o periodístico. Son conocidos algunos sucesos violentos en Valencia, Bilbao y Zaragoza a primeros de siglo, por no mencionar el motín anticlerical más conocido, la Semana Trágica barcelonesa, donde algunos de sus episodios fueron atribuidos a los lerrouxistas.

En cuanto a la naturaleza de este entusiasmo y la condición de sus protagonistas Elías de Mateo señaló que, en lo fundamental, una diferencia los separaba en su empeño por la violencia física y la acción directa. Los círculos confesionales mostraban un elitismo que de forma natural los enfrentaban con las masas anticlericales:

«Su carácter minoritario y escogido, el respaldo incondicional de las autoridades eclesiásticas, y en muchos casos de las civiles, hacían que su violencia fuese más selectiva y estuviese legitimada por los poderes establecidos» 24 .

Este respaldo de las autoridades a la, digamos, violencia clerical es el que advierte Ponce de León en el documento que comentamos en este artículo: una empresa soterrada y oscura con el propósito de derribar labor que durante décadas mantuvo a la logia Virtud en el ejercicio de la caridad. Reproducimos algunas líneas

\footnotetext{
22 «En el Círculo Republicano. Conferencia», El Popular, 1 de julio de 1919.

23 «Los católicos contra Roma», Andalucía Masónica, núm. 5. Málaga, noviembre de 1907, pág. 5.

24 De Mateo Avités, E. 1997: El apogeo del clericalismo a principios del siglo xx. El caso de Málaga, en Ayer, núm. 27, pág. 138.
} 
significativas de dicha carta de 1921 en la que se lamenta del acoso y las traiciones que sufren:

«Pero el elemento clerical que hace años nos persigue y por cuantos medios está a su alcance, hace lo posible por destruir la Logia Virtud, única que queda gracias a mi constancia y a mis desvelos en unión de un reducido número de buenos masones aunque sea inmodestia decirlo de 14 ó 18 logias que aquí existían, entre ellas dos portuguesas, enterados de nuestro nuevo domicilio, visitaron al dueño de la casa y consiguieron que nos despidieran por acta notarial».

«En más de treinta años que llevo de vida activa, me han combatido los elementos clericales y fanáticos de una manera espantosa, procurando perjudicarme en todo, quitándome clientes, haciendo denuncias falsas que se sobreseían enseguida libremente, haciendome perder una de mis carreras, por lo que tuve que emprender otras, y valiéndose aquellos elementos de todos los medios para conseguir el fin deseado, que es el de concluir de una manera definitiva con el único centro masónico que existe (en Málaga y su provincia), y como esta lucha de los enemigos de la luz y toda clase de progresos me alienta en lugar de acobardarme, me rejuvenece y me siento cada día más fuerte para sostenerla, aquellos han emprendido otro camino, el de meter la cizaña en casa, procurando formar un grupito que perturbe constantemente y comprando algunas conciencias, como se demuestra con el acta de abjuración de la masonería que acompaño, hecha por un hermano que se dio en esta de alta, procedente y recomendado por la Logia hermana de Cádiz, todo ello para que se desalienten los buenos y triunfe el mal sobre la razón y la virtud. Aunque es muy difícil y realmente no sé combatir contra la ingratitud y la perfidia que anida entre nosotros, no obstante, espero que el nuevo plan de ataque será deshecho y una vez más, la Logia Virtud, saldrá triunfante de sus enemigos, hoy encubiertos» 25 .

Debemos hacer notar en ese mismo texto que el propio Ponce de León manifiesta que el enemigo no es sólo el jesuitismo, sino algunos hermanos discrepantes. El conflicto, el enemigo es, además, la disidencia interna. Continúa el Venerable José Ponce de León:

«Algunos hermanos díscolos o mal aconsejados (por otros que no están en activo hace tiempo y que desde la sombra en unión de elementos pertubadores que en ninguna parte caben trabajan para apoderarse de la Logia y convertirla en un centro para otros fines, cubriéndola con la careta de la Teosofía que tampoco conocen) han querido que yo protestase ante el Gobierno... »26

La careta de la Teosofía. Sería un tema a desarrollar en otro lugar. Sólo mencionar aquí que algunos miembros de la Orden se dedicaron a fundar reiteradamente asociaciones de estudios teosóficos en Málaga durante la Dictadura de Primo de Rivera. Alguno de ellos, característicamente, fue durante años el Secretario de la Logia Virtud. Aquí únicamente anticiparemos que Martín de Leiva solicitó baja

25 Carta de José Ponce de León y Correa, Al Soberano Consejo de Gobierno. Málaga, 3 de abril de 1921. AHNS 764/12.

26 Ibíd. 
ya en 1917: «Se ha expedido plancha de quite por ausentarse de ésta al Secretario Martín de Leiva Martín, simb. '. Henry George, gr. ' $3 .^{0{ }{ }^{27}}$.

Posteriormente fue miembro fundador, ejerciendo diversos cargos, de la «Rama Teosófica Maitreya» (mayo de 1925), «Orden de la Estrella de Oriente» (julio de 1925) y «Rama Teosófica Pitágoras» (agosto de 1926). Otros miembros de la masonería local como Serafín García Moya, Simb. Nakens, o Ramón Muntadas, Simb. Macaud, también participaron en estas iniciativas ${ }^{28}$.

\section{CONCLUSIÓNES}

María José Lacalzada destacó que «la neutralidad ante las diferentes religiones que teóricamente debiera animar la actitud de todo buen masón, no fue factible en España ${ }^{29}$. Puede percibirse en este conflicto no sólo una lucha por apropiarse de la exclusiva legitimidad del ejercicio del bien y de la caridad ${ }^{30}$, aunque permanezca, por otra parte, esa voluntad de modelar la sociedad según una visión o versión del mundo y la realidad. La Logia «Virtud»,

«que por espacio de treinta años venía activamente trabajando en pro de nuestra augusta institución, practicando innumerables actos de caridad, dando de comer al hambriento, vistiendo al desnudo, atendiendo a masones y a profanos en sus enfermedades sin distinción de ideas políticas ni religiosas de clase alguna y contribuyendo al sostenimiento de escuelas y a la difusión de las ideas de libertad y progreso» ${ }^{31}$.

Finalmente unas palabras del federal y profesor Tomás Alonso López, que expone y alecciona desde las páginas de Andalucía Masónica sobre la virtud de la tolerancia, sobre el respeto que se deben los adversarios ideológicos. Quizá fuera un intento no del todo estéril por acercar posiciones simbólicamente discordantes:

«El corazón humano es tenebroso y las malas como las buenas acciones son hijas del sentimiento; no son exclusivas de ninguna escuela, secta o partido y se realizan por impulso natural.

${ }^{27}$ Logia Virtud, «Al llustre y Poderoso Hermano Gran Maestre. Madrid», Málaga, 18 de abril de 1917. AHNS, 764/12.

28 Véase Reglamento de la Sociedad Teosófica «Rama Maitreya». Málaga, 1 de mayo de 1925; Reglamento de la «Orden de la Estrella de Oriente Grupo núm. 1». Málaga, 1 de julio de 1925; Reglamento de la Sociedad Teosófica «Rama Pitágoras». Málaga, 1 de julio de 1926. AGCMa.

29 LACAlZADA DE MATEO, M. J. 2006: Mujeres en Masonería. Antecedentes históricos entre las luces y las sombras (1868-1938). Premià de Mar, Clavell Cultura, pág. 200.

${ }_{30}$ El director de El Popular, José Cintora, Simb. Leónidas, preguntaba: «¿qué mejor hermano y amigo puede encontrar el hombre, más que el hombre mismo?». Véase «Fraternidad y Filantropía», en Andalucía Masónica, núm. 4. Málaga, octubre de 1907, págs. 6-7.

31 Logia Virtud. Copia de libro de actas. Ten. . preparatoria para levantar nuevas ccol.. de un temp. : dedicado a la Virtud, Trabajo y Fraternidad masónica, celebrado el día 20 Mayo 1916. AHNS $764 / 12$. 
La educación, la instrucción y las leyes y las costumbres modifican el sentimiento; pero no le alteran substacialmente.

Entre los católicos hay hombres buenos y malos, como entre los librepensadores. Los carlistas, en general, no son ni más ni menos virtuosos que los anarquistas, ni más ni menos fanáticos y quizá ni más ni menos ilusos.

Es preciso no olvidar las enseñanzas de la Historia para ser tolerantes con las ideas de los demás, sin dejar de defender las propias con todo el celo de que el hombre sea capaz»32.

32 «La mutua tolerancia», en Andalucía Masónica, núm. 15. Málaga, 31 de octubre de 1908, pág. 8. 